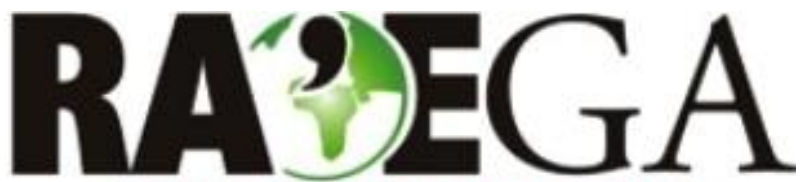

O ESPACCO GEOGRÁFICO EM ANÁLISE

\title{
O USO DE SISTEMAS DE INFORMAÇõES GEOGRÁFICAS NA IDENTIFICAÇÃO DE ÁREAS PRIORITÁRIAS PARA RECUPERAÇÃO E APROVEITAMENTO MINERAL NO LITORAL NORTE DE SÃO PAULO
}

\author{
THE USE OF GEOGRAPHIC INFORMATION SYSTEMS TO IDENTIFY PRIORITY AREAS FOR RECOVERY AND \\ MINERAL EXPLOITATION ON THE NORTH COAST OF SÃO PAULO
}

\section{RESUMO}

Carlos Tadeu de Carvalho Gamba ${ }^{1}$, Marsis Cabral Junior ${ }^{2}$, Cláudio José Ferreira ${ }^{3}$

O Litoral Norte paulista constitui um dos principais polos turísticos do Estado. A atividade de mineração, principalmente dos materiais de empréstimo (saibro), apesar de ter deixado um legado negativo ao longo dos últimos 30 anos, sempre serviu de suporte para o desenvolvimento urbano, o que possibilitou o incremento da atividade turística na região. O presente estudo teve como objetivo identificar e quantificar os remanescentes da mineração de saibro, que apresentassem degradação do meio ambiente e risco às comunidades locais, com o intuito de classificar estas áreas quanto ao seu potencial de aproveitamento para exploração de recursos minerais. Para isso lançou-se mão dos Sistemas de Informações Geográficas (SIG) para gerar um modelo digital de elevação, a partir de redes irregulares triangulares (TIN) e se obter o volume das áreas. Posteriormente estas informações foram integradas, também em ambiente SIG, com os dados de degradação e risco para se chegar ao potencial de aproveitamento das áreas para a mineração. Os resultados alcançados mostram que 33\% das 226 áreas mapeadas apresentam alto potencial para aproveitamento de bens minerais, sendo capazes de sustentar a demanda de suprimentos de baixo valor unitário utilizados na construção civil. O aproveitamento também pode trazer benefícios ambientais uma vez que é capaz de minimizar os riscos ambientais deixados pelas frentes de lavra abandonadas e restringir a ampliação das áreas mineradas.

PALAVRAS-CHAVE: Mineração de saibro, degradação ambiental, Sistemas de Informações Geográficas, TIN.

\section{ABSTRACT}

The North Coast of São Paulo is one of the major tourist centers of the State. The mining activity, especially of borrow materials (saibro), despite having left a negative legacy over the past 30 years, has always been the support for urban development, which enabled the growth of tourism in the region. This study aimed to identify and quantify the remnants of saibro mining, with environmental degradation and risk to local communities in order to classify these areas by their potential for mineral resources exploitation. Geographic Information Systems (GIS) were applied to generate a Digital Elevation Model (DEM) from a Triangular Irregular Network (TIN), obtaining the volume of those areas. Subsequently, this information was integrated with the degradation and risk data to reach the potential use of areas for mining. The achieved results show that $33 \%$ of 226 mapped areas have high potential for exploitation of mineral resources, being capable of sustaining the demand for low unit value supplies used in construction. The use can also bring environmental benefits as it is able to minimize natural hazards left by the abandoned mining fronts and restrict the expansion of mining areas

KEY-WORDS: Borrow materials (saibro), mining, environmental degradation, Geographic Information Systems, Triangular Irregular Network

\section{Recebido em: 01/09/2015 - Aceito em: 23/01/2017}

\footnotetext{
${ }^{1}$ Instituto de Pesquisas Tecnológicas, São Paulo, SP, e-mail: carlosgamba@ipt.br

2 Instituto de Pesquisas Tecnológicas, São Paulo, SP, e-mail: marsis@ipt.br

${ }^{3}$ Instituto Geológico, São Paulo, SP, e-mail: cferreira@sp.gov.br
} 


\section{O USO DE SISTEMAS DE INFORMAÇÕES GEOGRÁFICAS NA IDENTIFICAÇÃO DE ÁREAS PRIORITÁRIAS PARA RECUPERAÇÃO E APROVEITAMENTO MINERAL NO LITORAL NORTE DE SÃO PAULO}

\section{INTRODUÇÃO}

A região do Litoral Norte do Estado de São Paulo constitui um dos principais polos turísticos do seu território, o que é fortemente determinado por suas características geoambientais, em especial por suas praias e extensas áreas verdes que as circundam (Figura 1). A geografia dessa faixa litorânea é marcada pela imposição de esporões da Serra do Mar e por pequenos maciços e morros isolados dos terrenos cristalinos pré-cambrianos diretamente sobre a orla oceânica, delineando um modelado de relevo peculiar e exuberante, com pequenas planícies e enseadas, que formam reentrâncias entre os esporões.

A crescente demanda por infraestrutura e serviços da atividade turística, que nos períodos de veraneio pode elevar o contingente populacional da região em até sete vezes, tem como um importante reflexo sobre as condições de suporte do meio físico na região, a expansão do consumo e a produção local de insumos minerais para a indústria da construção civil.

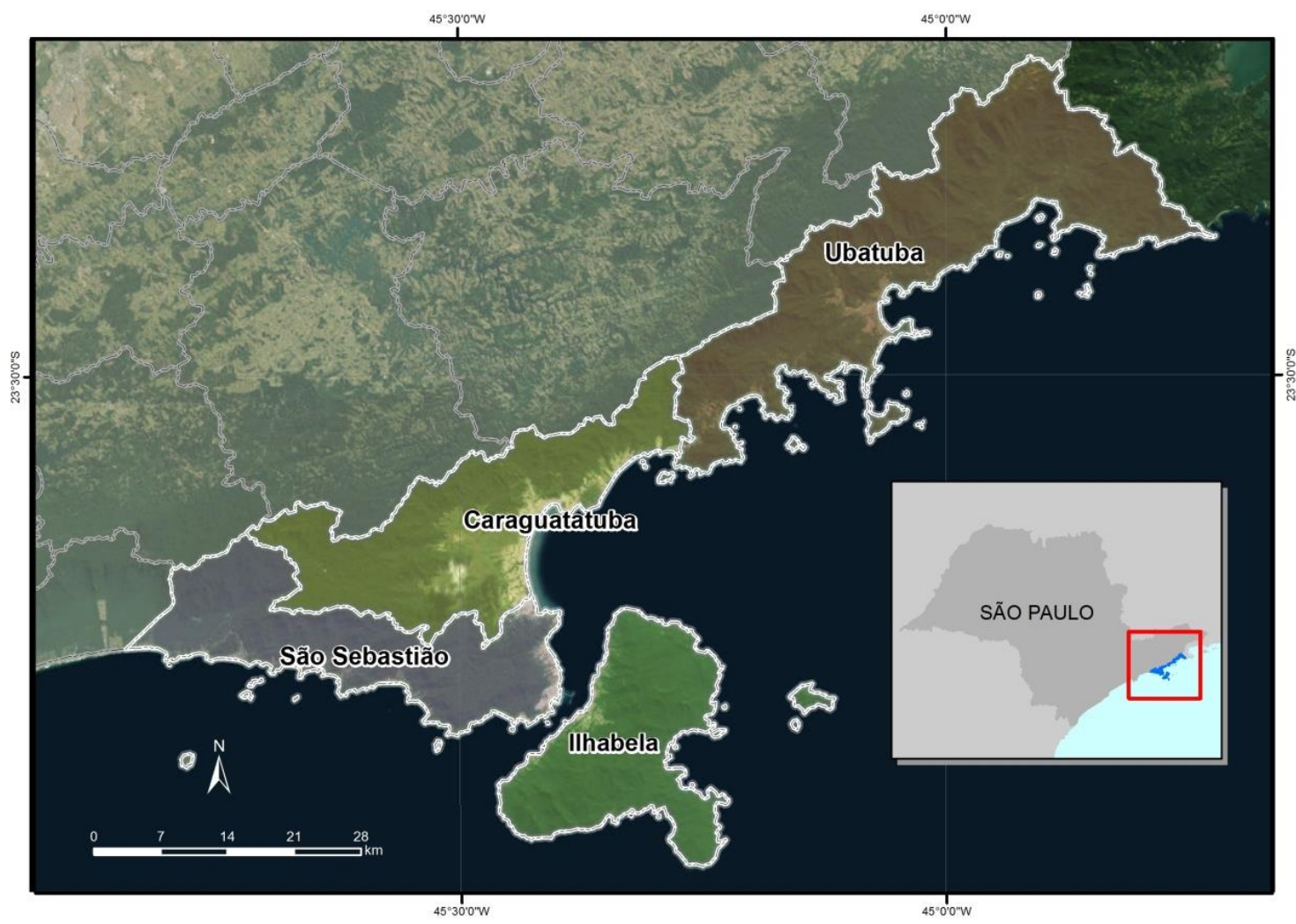

Figura 01 - Municípios do litoral norte paulista abrangidos pelo estudo.

Nesse contexto, um problema associado à evolução paisagística deste território vincula-se à atividade de mineração. Seu histórico tem como principais vetores de desenvolvimento a produção de granito ornamental e de substâncias minerais de uso in natura na construção civil, em especial, a lavra de materiais de empréstimo, ou saibro como são genericamente nominados na região.
Desde início da década de 1970, essa região setentrional do litoral paulista vem experimentando um vertiginoso crescimento urbano que, além dos fatores já citados, vem sendo impulsionado pelo aprimoramento da infraestrutura logística da região, marcado pelas melhorias dos acessos viários já existentes: Rodovia dos Tamoios (Caraguatatuba-São José dos Campos), Rodovia Oswaldo-Cruz (TaubatéUbatuba); e a abertura da BR-101, em seu trecho Ubatuba-Rio de Janeiro. 


\section{O USO DE SISTEMAS DE INFORMAÇÕES GEOGRÁFICAS NA IDENTIFICAÇÃOO DE ÁREAS PRIORITÁRIAS PARA RECUPERAÇÃO E APROVEITAMENTO MINERAL NO LITORAL NORTE DE SÃO PAULO}

A dinamização desse processo de urbanização provocou, desde o princípio, uma demanda crescente pelos insumos minerais de uso na construção civil. Limitada pela morfologia local, a ocupação foi se desenvolvendo preferencialmente nas faixas da planície costeira, entre os recortes serranos e, em vista das limitações geotécnicas desses terrenos sedimentares areno-argilosos, compostos por zonas alagadiças com nível freático próximo à superfície, sempre houve a necessidade de se utilizar materiais de empréstimo para o alteamento das construções, tanto para a infraestrutura pública (arruamentos e obras civis), como para empreendimentos particulares (lotes e condomínios).

Se por um lado a melhoria dos acessos viários estimulou a expansão urbana e, consequentemente, o consumo de materiais de empréstimo, a explotação de granito ornamental, que já vinha acontecendo pelo menos desde os anos de 1960, acentuou-se sobremaneira, em decorrência da maior facilidade de escoamento da produção.

No auge da produção do granito Verde Ubatuba, nos anos de 1980, havia cerca de 60 frentes de lavra sobre matacões, a grande maioria clandestina ou irregular. Estimativa relativa ao ano de 1985 (BITAR, 1990) indicava que o Granito Verde Ubatuba respondia por cerca de $11 \%$ das exportações brasileiras de rocha ornamental, a partir de uma produção anual estimada em $13.000 \mathrm{~m}^{3}$, o que equivaleria a cerca de 2.600 blocos retirados anualmente (volume bruto médio de $5 \mathrm{~m}^{3}$ ).

A despeito do alto valor comercial dessas rochas no mercado brasileiro e internacional, fatores como a informalidade de grande parcela dos empreendimentos, as condições tecnológicas precárias das lavras, desconsiderando os seus impactos ambientais, bem como a situação conflituosa com a expansão da ocupação imobiliária, as medidas de conservação ambiental e os exuberantes atrativos turísticos da região, fizeram por encerrar a produção local de granito ornamental no final dos anos de 1980. Entretanto, o mesmo não ocorreu com os materiais de empréstimo que, acompanhados pela produção de agregados, vem se desenvolvendo até os dias atuais.

O objetivo deste trabalho foi quantificar o montante de recursos minerais disponível em áreas já impactadas pela atividade mineral no Litoral Norte e identificar áreas que possam ser priorizadas para o seu aproveitamento e recuperação, com base em critérios de criticidade quanto à degradação e risco a eventos geodinâmicos.

Este estudo foi conduzido no âmbito de um trabalho mais amplo, orientado ao estabelecimento das bases técnicas para a formulação de um modelo de zoneamento minerário para a porção continental do Litoral Norte de São Paulo, com vistas ao ordenamento territorial e à promoção do desenvolvimento sustentável da atividade de mineração (GAMBA, 2013). Um dos pressupostos adotados para a formulação deste zoneamento considerou que áreas onde os impactos ao meio apresentassem depreciação do patrimônio paisagístico ou oferecessem risco à população ou aos equipamentos urbanos do entorno, deveriam ser consideradas prioritárias não só dentro da perspectiva da recuperação ambiental, mas também do aproveitamento das substâncias minerais remanescentes, visto que as atividades de finalização de um empreendimento de mineração são capazes de estabelecer procedimentos de recuperação ambiental, abrangendo, entre outros, a estabilização de encostas e a recomposição florestal . Tal medida constitui uma forma de garantir a melhoria da qualidade ambiental, restringindo o avanço da mineração para novas áreas e reabilitando parte do passivo existente, sem comprometer o aproveitamento da dotação mineral da região (CABRAL JUNIOR e GAMBA, 2014).

PROBLEMAS GERADOS PELA
MINERAÇÃO DE SAIBRO
Os materiais para a construção civil
detém uma importância estratégica para o
desenvolvimento dos municípios do Litoral Norte.
Isso ocorre, notadamente, com o saibro, por seu




\section{O USO DE SISTEMAS DE INFORMAÇÕES GEOGRÁFICAS NA IDENTIFICAÇÃOO DE ÁREAS PRIORITÁRIAS PARA RECUPERAÇÃO E APROVEITAMENTO MINERAL NO LITORAL NORTE DE SÃO PAULO}

uso generalizado em obras de infraestrutura civil e na manutenção e aprimoramento da rede viária.

No entanto, o histórico do aproveitamento dessas substâncias minerais deixou um legado ambiental negativo na região. Mesmo se tratando de bens minerais abundantes, que não demandam tecnologias sofisticadas para a sua produção, seu aproveitamento desordenado e sem compromisso com o controle dos impactos e a adequada finalização das lavras, acarretou acentuada degradação do meio ambiente (FERREIRA et al. 2005; FERREIRA et al. 2008a, b). Até a década de 1990, a maioria dos empreendimentos de mineração no Litoral Norte paulista operava de forma ilegal. Apesar da ação fiscalizadora do poder público coibir quase que totalmente esse tipo de lavra irregular, não obteve o mesmo êxito na promoção da recuperação ambiental das áreas degradadas pela atividade de mineração (BROLLO et al. 2005, FERREIRA et al. 2006, FERREIRA et al., 2009).

Uma abordagem sistematizando as justificativas técnicas e os fundamentos conceituais e metodológicos para a priorização do aproveitamento dos recursos minerais, com base na recuperação ambiental das áreas degradadas e da redução de risco, foi estabelecida pelo IG - Instituto Geológico do Estado de São Paulo (SMA), em meados da década de 2000, dentro de um projeto que visava capacitar a Prefeitura do município de Ubatuba, com conhecimentos científicos a respeito da mineração de saibro, considerando os impactos existentes, os riscos associados, a situação legal dos empreendimentos e estabelecendo, a partir daí, prioridades e práticas adequadas que conciliassem a recuperação ambiental com a exploração sustentável dos bens minerais (FERREIRA, 2005).

Essa iniciativa encontrou suporte na própria legislação, uma vez que o avanço das pressões preservacionistas e a institucionalização de leis, criando regras específicas para ocupação do meio ambiente - no caso do Litoral Norte, o Zoneamento Ecológico Econômico, instituído pelo Decreto Estadual 49.215, de 7 de dezembro de 2004 - aliadas à própria vocação ambiental da região, estabeleceram uma série de restrições à expansão da atividade de mineração e, por consequência, passaram a exigir uma análise mais apurada das características e das potencialidades naturais do território em questão.

Os estudos desenvolvidos pelo IG se concentraram em quantificar a degradação e o risco vinculados a estes remanescentes a fim de identificar a possibilidade de aproveitamento do material disponível. O trabalho foi realizado, inicialmente, em 116 áreas, no município de Ubatuba. Posteriormente, as informações sobre degradação e risco das áreas foram extrapoladas pra todo território do Litoral Norte, chegando a um total de 324 áreas cadastradas (FERREIRA, 2012; FERREIRA e CRIPPS, em preparação).

\section{METODOLOGIA}

Os procedimentos metodológicos adotados neste trabalho foram escolhidos com o objetivo de utilizar as funcionalidades presentes em um SIG para extrair informações de volume, na superfície, e conjugá-las com dados de risco e degradação a fim de se obter um indicativo sobre o potencial de aproveitamento de matériasprimas minerais, a partir de três indicadores.

\section{A SELEÇÃO DAS ÁREAS}

Para localização das áreas prioritárias para recuperação e aproveitamento, utilizou-se como referência os levantamentos executados pelo IG em todo o território do Litoral Norte até o ano de 2012. Todas as poligonais foram revistas e atualizadas com base na situação atual do uso e da cobertura da terra atual. Como referência, foram utilizadas as imagens do Satélite RapidEye de 2012, com resolução espacial de 5 metros, e para auxiliar o processo de fotointerpretação, a ferramenta Google Earth, que fornece um conjunto de mosaicos de imagens de alta resolução e permite identificar feições de proporções métricas. Complementarmente foram feitas observações em campo. Os dados 


\section{O USO DE SISTEMAS DE INFORMAÇÕES GEOGRÁFICAS NA IDENTIFICAÇÃO DE ÁREAS PRIORITÁRIAS PARA RECUPERAÇÃO E APROVEITAMENTO MINERAL NO LITORAL NORTE DE SÃO PAULO}

foram padronizados dentro no Sistema Universal Transverso de Mercator (UTM) utilizando o Datum Planimétrico WGS84 zona 23S.

Foram selecionadas 228 áreas das 324 anteriormente cadastradas pelo IG. $\mathrm{Na}$ depuração dessa base de dados, foram excluídas as áreas oneradas por títulos minerários autorizativos onde se constatou a existência de atividade de mineração (minas em operação) e os locais com nítida reabilitação das condições naturais, geralmente caracterizados pela recomposição florestal do meio. Alguns polígonos originalmente mapeados foram desmembrados, nas situações em que o perímetro delimitado se sobrepunha a equipamentos urbanos.

\section{O CÁLCULO DO POTENCIAL MINERAL}

O potencial mineral é definido pela capacidade de uma área portar quantidades significativas de determinada substância, a ponto de torná-la viável economicamente para a exploração mineral.

Nessa região litorânea, a associação entre clima, geologia e geomorfologia permite que haja uma oferta abundante de matériasprimas minerais, uma vez que grandes volumes de materiais de empréstimo podem ser explotados na base das vertentes que se espalham pelo território litorâneo.
A quantificação do volume disponível nestas áreas é facilitada pelo fato de que elas geralmente se encontram associadas a superfícies inclinadas, onde a intervenção dos equipamentos é mais favorável, e a referência topográfica, como por exemplo, um modelo digital do terreno pode ser utilizado para o cálculo. No Litoral Norte, Ferreira e Fernandes da Silva (2008) lançaram mão de sistemas de informações geográficas para realizar cálculos de volume sobre grades regulares geradas a partir de dados topográficos do município de Ubatuba. À época, para a construção deste modelo, foram utilizadas as curvas de nível disponíveis nas escalas 1:10.000 e 1:50.000 para a região. No presente trabalho optou-se por adotar um procedimento similar, com a diferença que, em razão da disponibilidade de materiais, foram utilizadas apenas as curvas de nível na escala 1:50.000, e os cálculos de volume foram feitos sobre uma Grade Irregular Triangular (TIN) (Figura 2). Em ambos os trabalhos os mapas foram projetados no Sistema UTM (Fuso 23 Sul). Neste caso porém, o Datum Planimétrico SAD 69 foi substituído pelo Datum Planimétrico WGS 84. 


\section{O USO DE SISTEMAS DE INFORMAÇÕES GEOGRÁFICAS NA IDENTIFICAÇÃO DE ÁREAS PRIORITÁRIAS PARA RECUPERAÇÃO E APROVEITAMENTO MINERAL NO LITORAL NORTE DE SÃO PAULO}

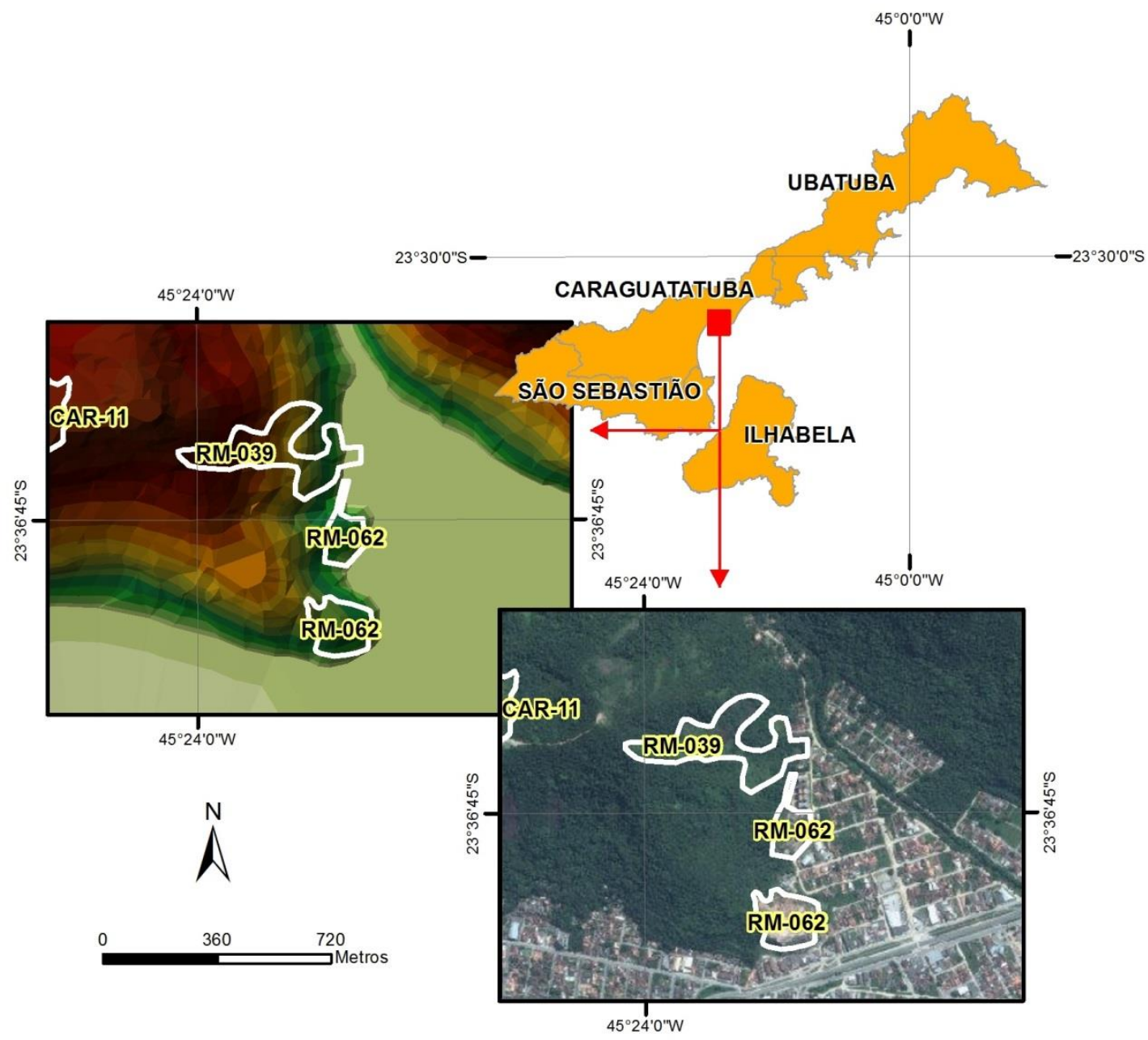

Figura 02 - Poligonais das áreas estudadas sobrepostas a um modelo digital do terreno elaborado a partir de uma TIN (à esquerda) e sobre uma imagem aérea (à direita), delimitando as áreas de interesse.

As grades irregulares triangulares, que na literatura técnica são conhecidas como TIN (Triangular Irregular Network), são modelagens em três dimensões, que geram um arquivo de estrutura vetorial, onde pontos amostrais da superfície são conectados a uma série de arestas formando triângulos.

No software $\operatorname{ArgGis}^{\circledR} 9.3$ esse método é construído a partir da Triangulação de Delaunay, um processamento de uso frequente para a interpolação de dados espaciais e a construção de modelos digitais em 3D (BARBOSA, et al.
2009). Segundo Piteri et al. (2007), o diferencial desta técnica, que a torna importante para diferentes aplicações, é que ela utiliza um critério de maximização dos ângulos mínimos de cada triângulo. Tal estratégia tende a evitar a formação de triângulos com ângulos internos muito pequenos, garantindo que nenhum vértice esteja dentro da circunferência formada por qualquer triângulo (Figura 3). 


\section{O USO DE SISTEMAS DE INFORMAÇõES GEOGRÁFICAS NA IDENTIFICAÇÃO DE ÁREAS PRIORITÁRIAS PARA RECUPERAÇÃO E APROVEITAMENTO MINERAL NO LITORAL NORTE DE SÃO PAULO}

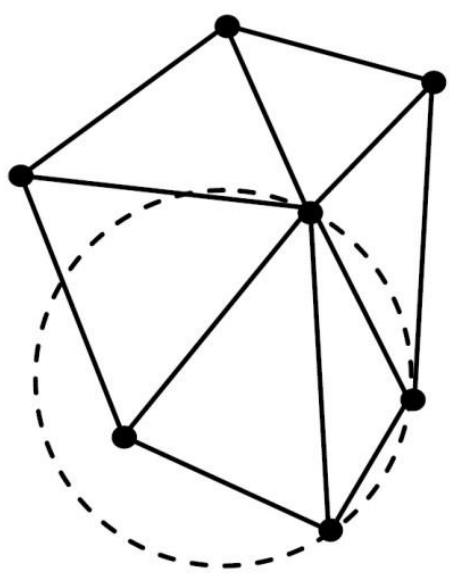

A

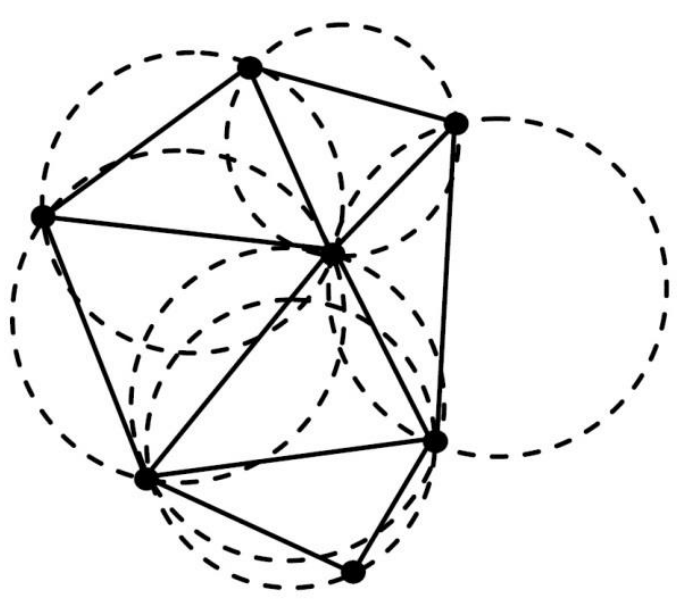

B

Figura 03 - Triangulação de pontos onde pode ser observado o não atendimento (A) e o atendimento (B) ao critério de Delaunay.

De acordo com Namikawa (1994), as grades irregulares triangulares possuem menos redundâncias que as grades regulares e por utilizarem os próprios pontos de amostras da superfície, aumentam a confiabilidade do modelo gerado. Para Lee (1991) e Felgueiras. (2001), uma das vantagens desta ferramenta é que, além de permitir uma série de cálculos sobre a elevação e o modelado, possibilita um melhor desempenho na representação das superfícies com topografia variada.

O cálculo de volume, também realizado dentro do software $\operatorname{ArcGis}^{\circledR}$ 9.3, foi feito a partir da projeção da poligonal, que delimita cada área impactada, sobre o modelo digital gerado pela TIN. O volume cúbico representa a área entre a porção selecionada da superfície e um plano horizontal definido pela altitude mínima onde o polígono se encontra.

Após a quantificação dos respectivos volumes, as áreas foram classificadas segundo a estimativa das reservas minerais remanescentes. Considerando que constituem sítios de exploração remanescentes, onde a atividade produtiva preexistente possivelmente já lavrou parte do material disponível, foi aplicada uma redução para $25 \%$ do total do volume obtido dentro do SIG. Incluem-se nesta dedução não só a perda estimada de material, mas também o montante necessário à estruturação da frente de lavra (formação de taludes e bancadas) e posterior estabilização e revegetação da área minerada. A partir daí foram estabelecidas três classes quanto às reservas geológicas potenciais: baixa, média e alta. São escalas indicativas do potencial volumétrico específicos para os materiais contidos nos mantos de alteração intempérica.

A definição das classes levou em conta o padrão produtivo das atuais minas de materiais de empréstimo, as quais operam em uma escala média de produção mensal da ordem de 10.000 $\mathrm{m}^{3}$. Valores situados na categoria de baixo potencial compreendem reservas de até 120.000 $\mathrm{m}^{3}$, o que corresponderia ao montante de material lavrado em período não superior a um ano. Apesar da baixa atratividade econômica, áreas com esta dimensão de reservas poderiam suprir demandas de obras privadas locais, ou mesmo constituir caixas de empréstimo para uso das próprias prefeituras. As reservas de potencial médio abrange a faixa volumétrica entre 120.000 e $400.000 \mathrm{~m}^{3}$. Nesta classe intermediária incluem-se as áreas passíveis de serem explotadas durante cerca de três anos, que corresponde ao período de vigência de uma licença ambiental. Acima de $400.000 \mathrm{~m}^{3}$ enquadram-se as áreas de alto potencial, e 


\section{O USO DE SISTEMAS DE INFORMAÇÕES GEOGRÁFICAS NA IDENTIFICAÇÃOO DE ÁREAS PRIORITÁRIAS PARA RECUPERAÇÃO E APROVEITAMENTO MINERAL NO LITORAL NORTE DE SÃO PAULO}

representam as áreas de maior atratividade em relação às reservas geológicas potenciais.

\section{O RISCO E A DEGRADAÇÃO COMO VARIÁVEIS GEOAMBIENTAIS}

Para concluir esta etapa do presente estudo, as informações de volume foram conjugadas, com os dados de risco e degradação. Com isso, os procedimentos metodológicos aqui estabelecidos a partir da proposta de Ferreira e Fernandes da Silva (2008), Ferreira et al. (2008a, b) e Ferreira (2012), fundamentam-se na quantificação de três fatores geoambientais: risco, degradação e potencial mineral das áreas impactadas na região.

$O$ risco refere-se aos perigos potenciais e às condições de vulnerabilidade que, juntos, são capazes de provocar perda de vidas, ameaças à infraestrutura, aos meios de produção ou ao próprio meio natural do qual a sociedade depende (NOGUEIRA et al., 2013).

A definição do índice que quantifica esse risco é dada pela equação:

$\mathrm{R}=\mathrm{P} \times \mathrm{V} \times \mathrm{D}$

Onde, $\mathrm{R}=$ risco; $\mathrm{P}=$ perigo $\mathrm{a}$ evento de deslizamento de massa;

$V=$ vulnerabilidade do elemento em risco; $D=$ exposição (dano) do elemento em risco (FERREIRA, 2012).

Estas variáveis estão diretamente ligadas ao perfil topográfico do terreno, às características do solo e do entorno da área em questão. Áreas de maior declividade, circunscritas por vizinhanças densamente povoadas ou dotadas de um maior número de equipamentos urbanos, tendem a apresentar um risco mais elevado a eventos indesejados.

A degradação é tratada pelo artigo 3 , inciso II da Lei Federal no 6.938 como a alteração adversa das características do meio ambiente. Sinteticamente, diz respeito às áreas onde o meio físico é apropriado de maneira inadequada tendo como resultado a esterilização ou redução de suas características naturais e consequentemente de sua capacidade produtiva.

Adicionalmente, a degradação pode potencializar os processos erosivos e a perda de biodiversidade.

O índice de degradação é dado pela equação:

$D=E \times 0,353+Q \times 0,399+$ Se $\times 0,184+V h \times$ 0,064

Onde, $\mathrm{D}=$ degradação; $\mathrm{E}$ = processos erosivos; $\mathrm{Q}$ $=$ irregularidades

do terreno; $\mathrm{Se}$ = área de solo exposto; $\mathrm{V}$ = área de vegetação herbácea-arbustiva (FERREIRA, 2012; FERREIRA et al., 2008a, b).

Os pesos para cada variável são definidos pela técnica AHP - Processo Analítico Hierárquico (SAATY, 2008), de maneira que cada variável é ponderada a partir do seu grau de importância dentro do processo. $O$ resultado é obtido por meio da comparação das variáveis por pares (pairwise). A Tabela 1 apresenta um exemplo de como o cálculo deste índice é feito:

Tabela 01 - Exemplo de cálculo do índice de degradação para a área RM-368 
GAMBA, C.T.C., CABRAL JUNIOR, M, e FERREIRA, C.J.

O USO DE SISTEMAS DE INFORMAÇÕES GEOGRÁFICAS NA IDENTIFICAÇÃO DE ÁREAS PRIORITÁRIAS PARA RECUPERAÇÃO E APROVEITAMENTO MINERAL NO LITORAL NORTE DE SÃO PAULO

\begin{tabular}{|c|c|c|c|c|}
\hline Indicador & $\begin{array}{l}\text { Parâmetro } \\
\text { medido }\end{array}$ & $\begin{array}{c}\text { Valor } \\
\text { normalizado }\end{array}$ & $\begin{array}{c}\text { Valor final } \\
\text { normalizado }\end{array}$ & Peso* \\
\hline Processos erosivos (E) & Linhas de erosão & 0,53 & 0,53 & 0,353 \\
\hline \multirow{3}{*}{$\begin{array}{l}\text { Irregularidade } \\
\text { do terreno }(Q)\end{array}$} & Amplitude & 0,12 & & \\
\hline & Declividade média & 0,65 & 0,46 & 0,399 \\
\hline & $\begin{array}{c}\text { Linha de quebra } \\
\text { de taludes }\end{array}$ & 0,75 & & \\
\hline Solo exposto (Se) & Área & 0,05 & 0,05 & 0,184 \\
\hline Vegetação (Vh) & Área & 0,092 & 0,092 & 0,064 \\
\hline
\end{tabular}

Fonte: adaptado de Ferreira et al. (2008a)

\section{DISCUSSÃO DOS RESULTADOS}

Os resultados foram consolidados em um plano de informação contento a espacialização atualizada das áreas degradadas juntamente com os seus respectivos atributos: índice de potencial mineral, risco e degradação, os dois

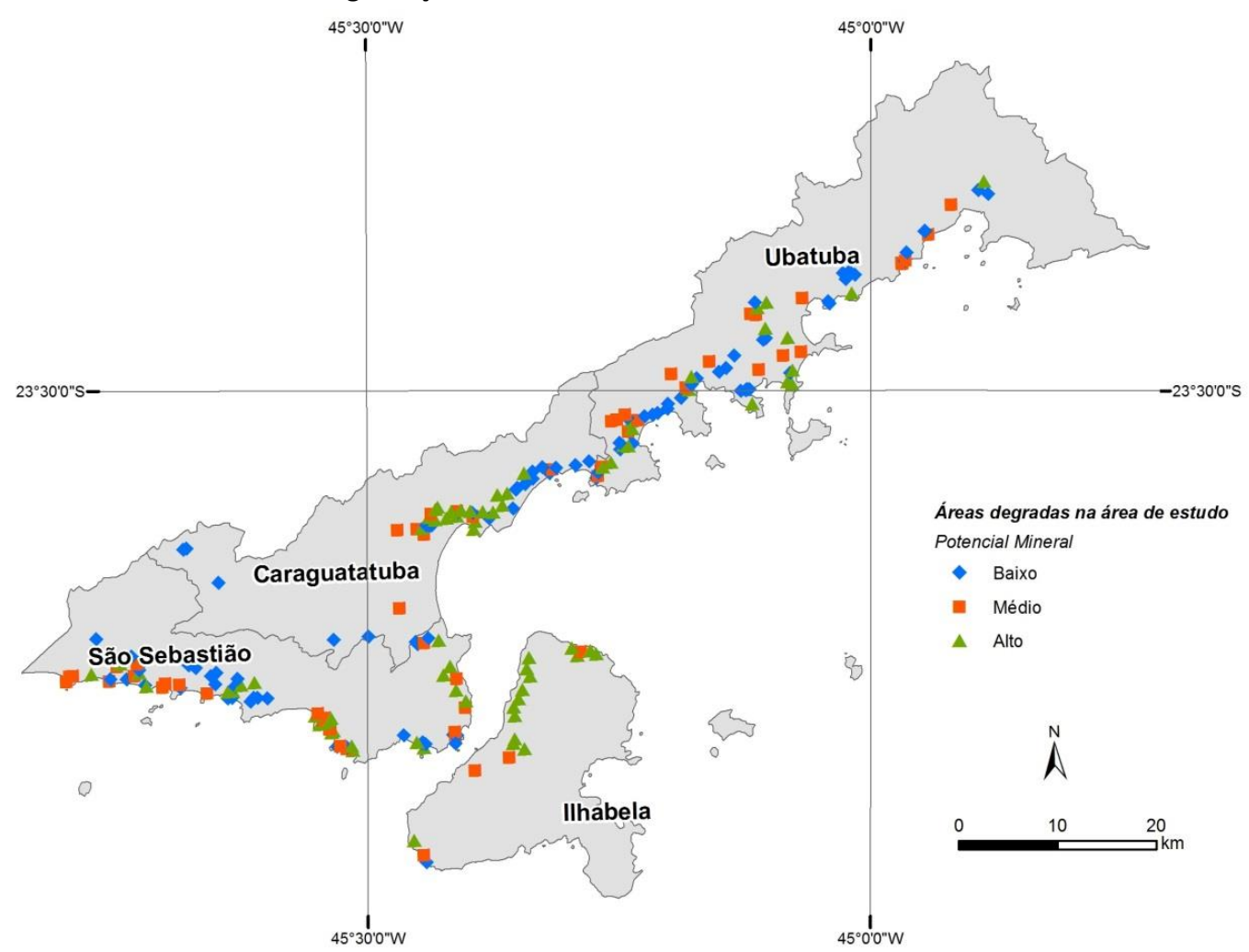

últimos incorporados da base de dados do IG. A distribuição destas áreas pode ser observada na Figura 4.

Figura 04 - Distribuição pontual das áreas degradadas com identificação da classe de potencial mineral.

Uma visão integrada da distribuição dos dados parametrizados, que qualificam as áreas degradadas, pode ser visto na Figura 5. 


\section{Áreas de interesse no Litoral Norte}

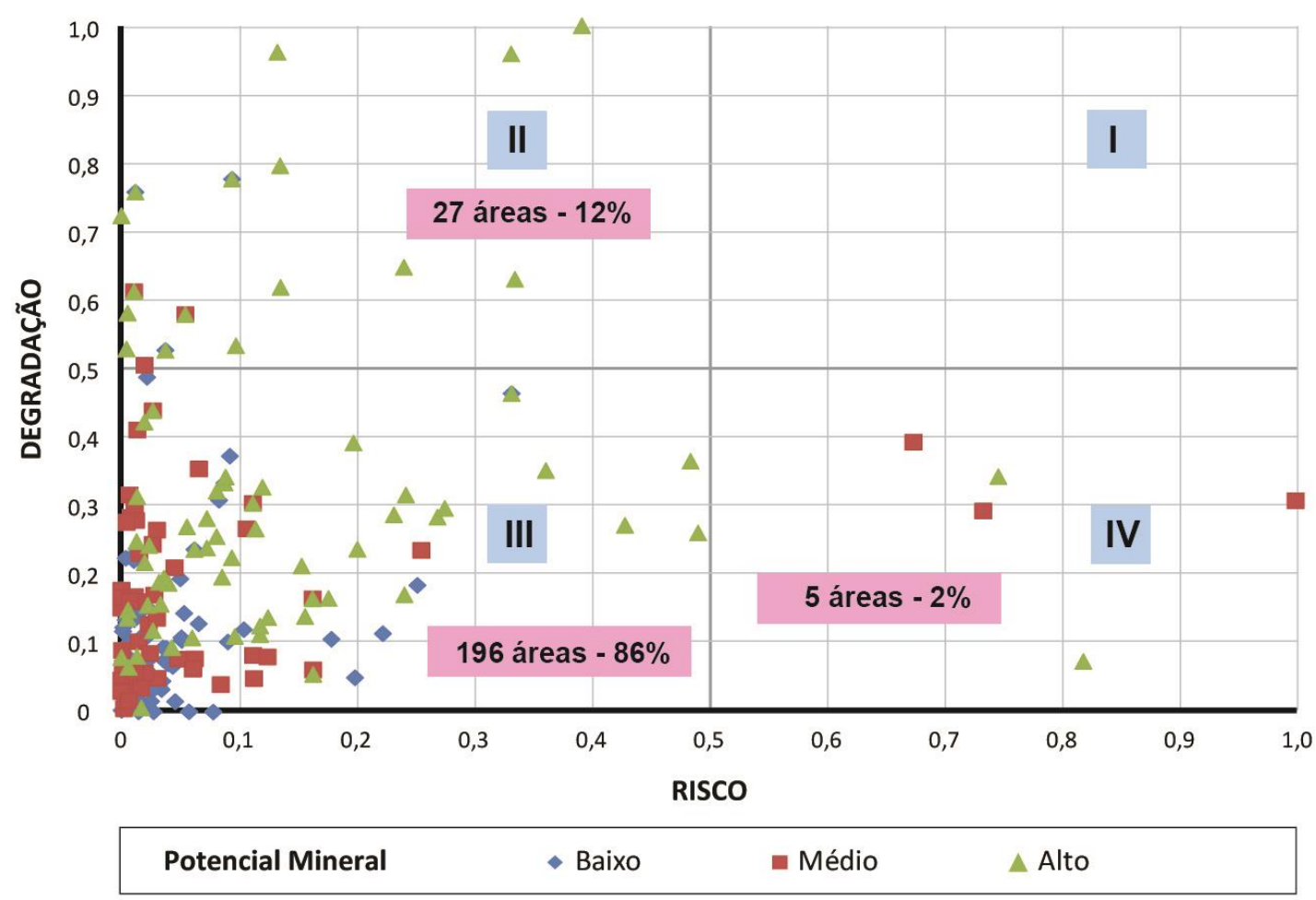

Figura 05 - Gráfico risco versus degradação das áreas mineradas em encostas do Litoral Norte com a classificação do potencial mineral - dados normalizados no território dos quatro municípios

Constata-se que a maior parte das áreas delimitadas nas poligonais encontra-se em situação de baixos índices de degradação e risco (196 polígonos - 86\%). Os demais polígonos ou se enquadram como de alta degradação (27 polígonos - 12\%), ou de alto risco (apenas 5 polígonos - 2\%). Segundo os critérios de risco e ambiental, as áreas mais suscetíveis são aquelas posicionadas nos quadrantes II e IV da Figura 5. As figuras 6 a 9 ilustram a parametrização das áreas degradadas dentro de cada território dos quatro municípios.

Os dados individualizados e normalizados por município mostram que, relativamente, Caraguatatuba concentra as áreas de degradação mais elevadas, destacando-se que todos os polígonos nessas situações estão enquadrados na categoria de alto potencial mineral (Figura 6). 


\section{Áreas de interesse no município de Caraguatatuba}

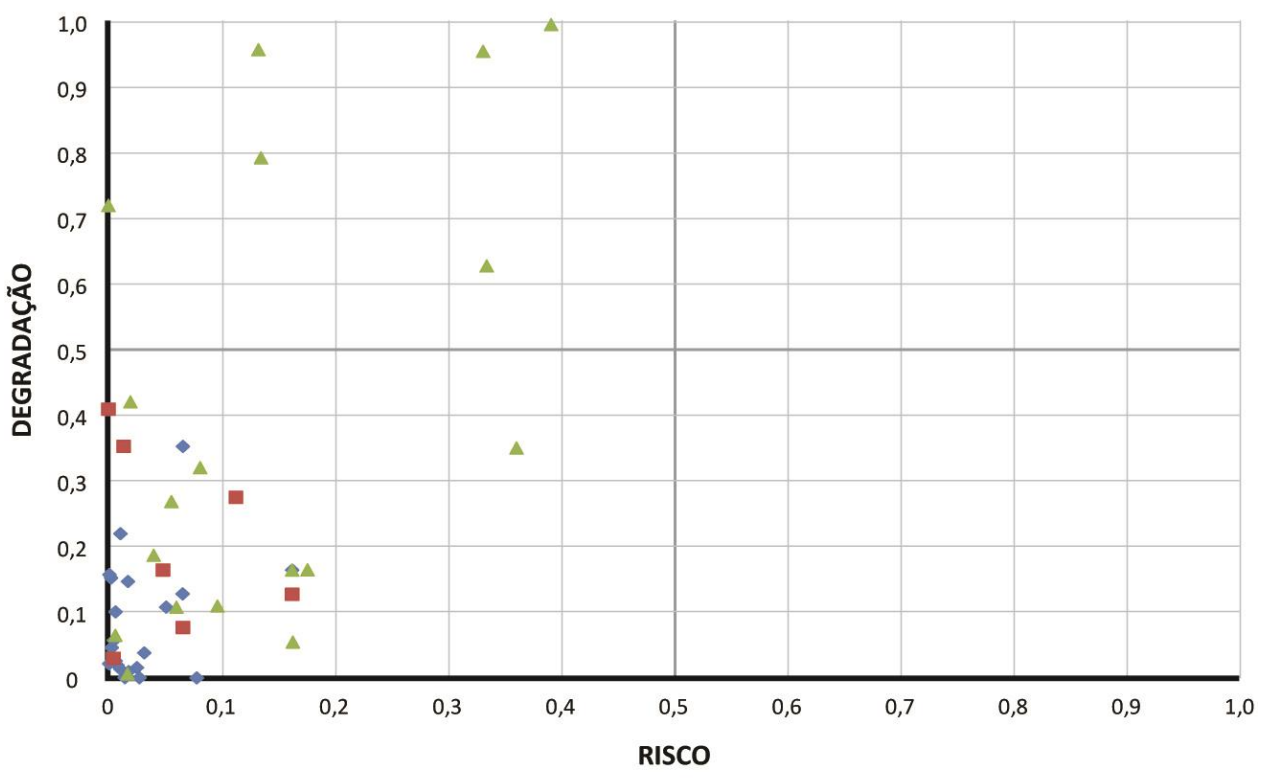
Potencial Mineral
- Baixo
- Médio
$\triangle$ Alto

Figura 06. Gráfico risco versus degradação das áreas mineradas em encostas, com a classificação do potencial mineral em Caraguatatuba/SP.

Áreas de interesse no município de llhabela



Figura 07. Gráfico risco versus degradação das áreas mineradas em encostas, com a classificação do potencial mineral em Ilhabela/SP 
Áreas de interesse no município de São Sebastião

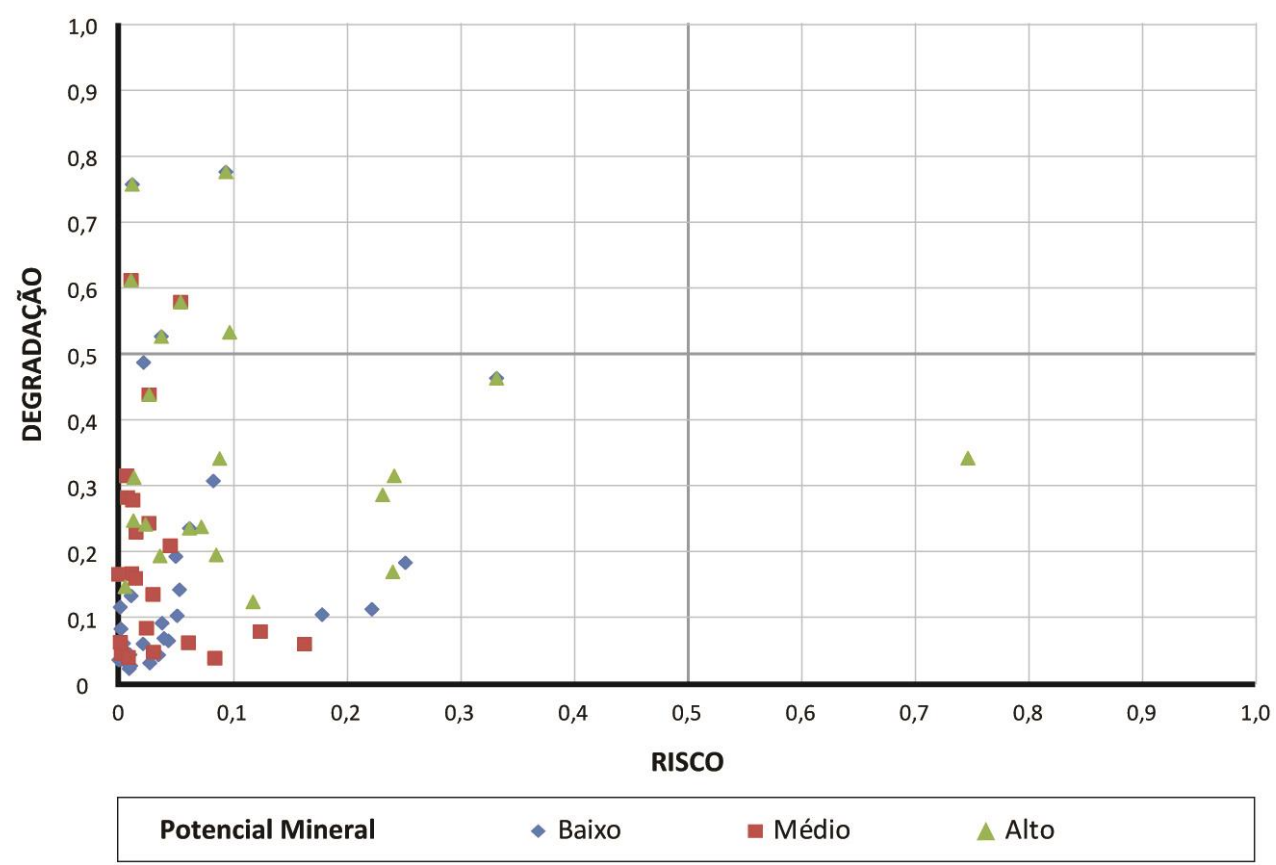

Figura 08. Gráfico risco versus degradação das áreas mineradas em encostas, com a classificação do potencial mineral em São Sebastião/SP

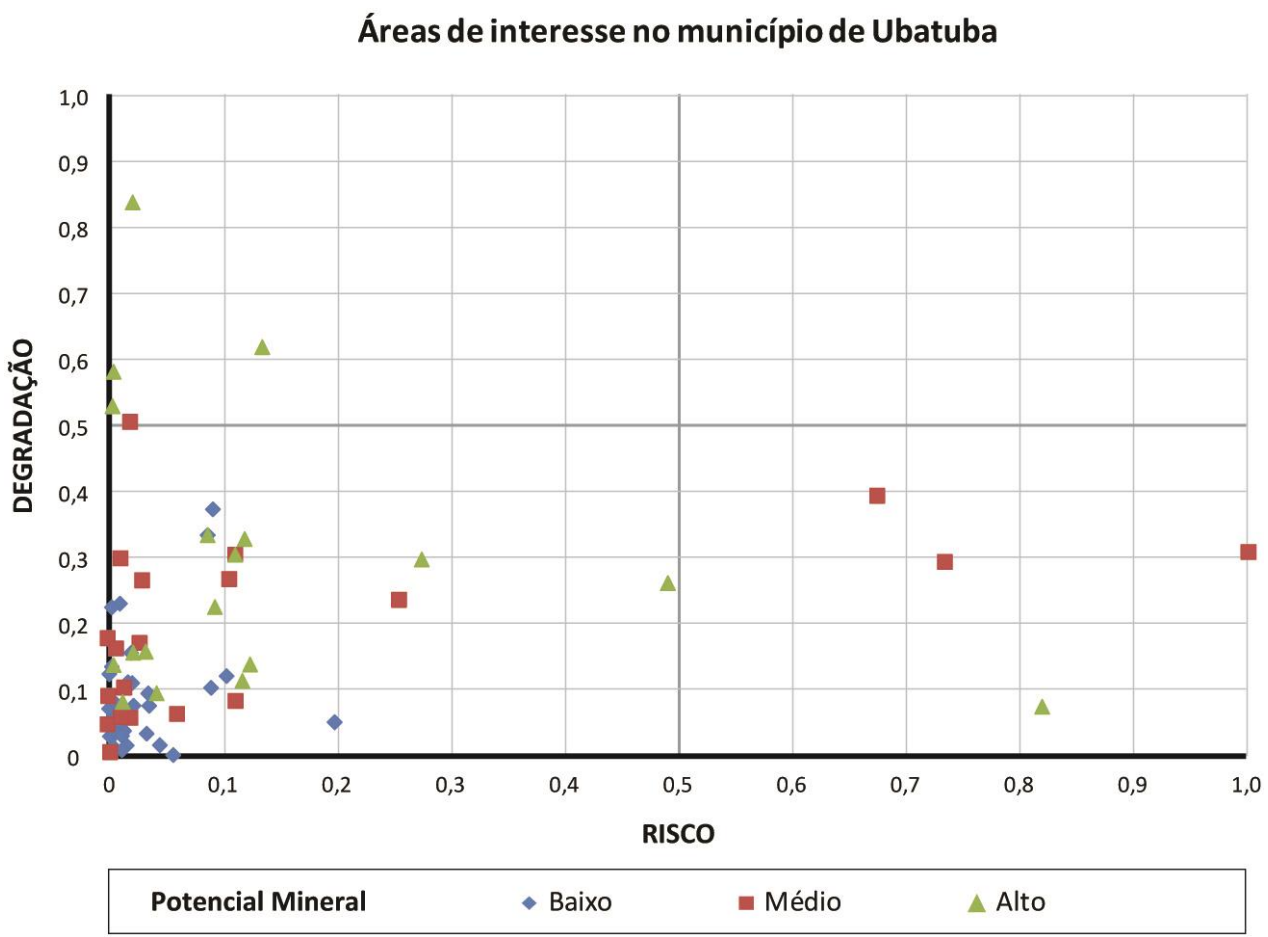

Figura 09. Gráfico risco versus degradação das áreas mineradas em encostas, com a classificação do potencial mineral Ubatuba/SP 


\section{O USO DE SISTEMAS DE INFORMAÇõES GEOGRÁFICAS NA IDENTIFICAÇÃO DE ÁREAS PRIORITÁRIAS PARA RECUPERAÇÃO E APROVEITAMENTO MINERAL NO LITORAL NORTE DE SÃO PAULO}

No município de Ilhabela (Figura 7), nota-se uma forte presença de áreas com alto potencial de aproveitamento mineral, o que é fortemente influenciado pela dimensão e declividade das áreas, apesar de parte delas estarem sobrepostas à Unidades de Conservação de Proteção Integral (Figura 10). Junto de Caraguatatuba, é o único onde se observa a conjugação de alto potencial, risco e degradação

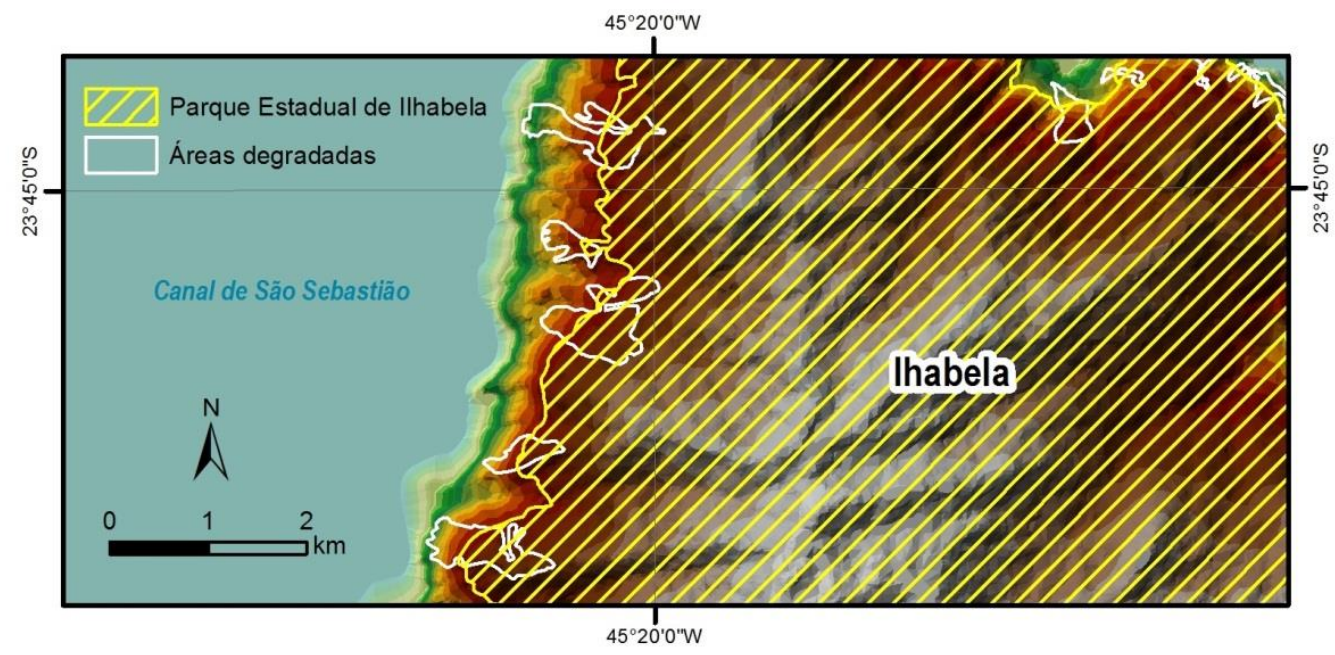

Figura 10. Localização de áreas degradadas com alto potencial de aproveitamento de substâncias minerais se sobrepondo sobre os limites do Parque Estadual de Ilhabela em Ilhabela/SP.

No município de São Sebastião, locais que apresentam boa expectativa de aproveitamento encontram-se, em sua maioria, associados a áreas degradadas, tendência também observada no município de Ubatuba. Entretanto, no segundo caso, há uma ocorrência maior de riscos associados.
Especificamente com relação ao potencial mineral, em função dos critérios adotados em termos de sua qualificação, foram caracterizadas com baixo potencial de reservas 97 áreas, 56 com médio e 75 com alto (Figura 11). A distribuição dessas áreas entre os territórios pode ser vista na Figura 12. 
Potencial Mineral

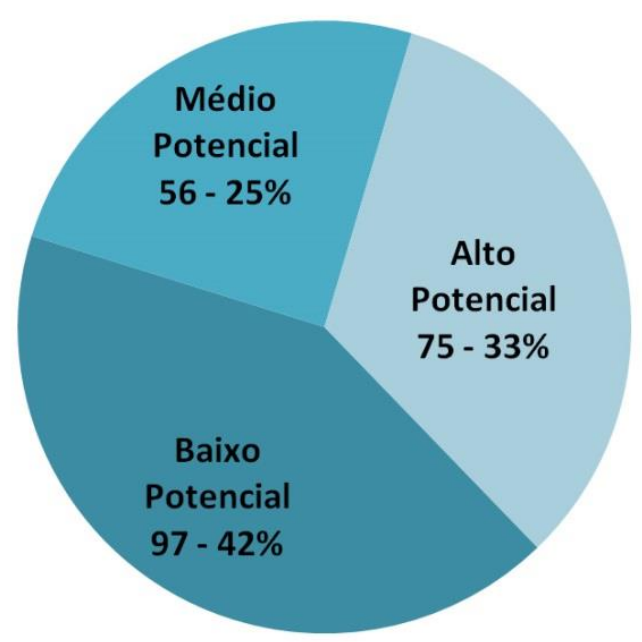

Figura 11. Quantificação das áreas degradadas segundo o potencial mineral.

\section{Potencial Mineral}

Alto Médio Baixo

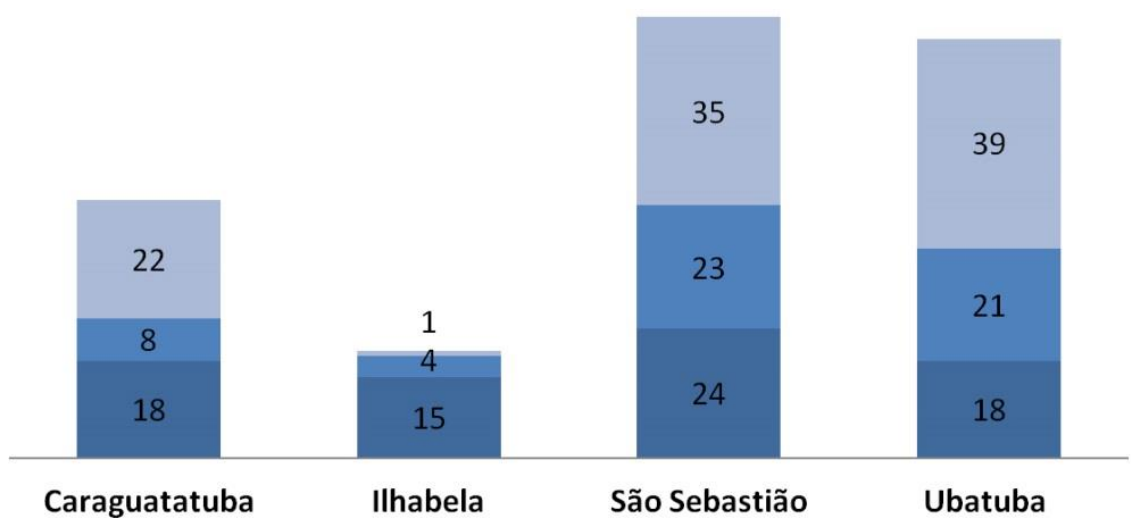

Figura 12. Potencial mineral - distribuição das áreas por município.

Para ilustrar a expressiva dimensão do potencial de reservas geológicas de substâncias minerais de uso como materiais de empréstimo associadas às áreas degradadas, verifica-se que, apenas nos polígonos delimitados como de alto potencial, as reservas estimadas nos quatro municípios totalizam cerca de 187 milhões de $\mathrm{m}^{3}$. Desse total, 39 áreas possuem reservas potencialmente aproveitáveis superiores a 1 milhão de toneladas (figuras 13 e 14). 


\section{O USO DE SISTEMAS DE INFORMAÇÕES GEOGRÁFICAS NA IDENTIFICAÇÃO DE ÁREAS PRIORITÁRIAS PARA RECUPERAÇÃO E APROVEITAMENTO MINERAL NO LITORAL NORTE DE SÃO PAULO}

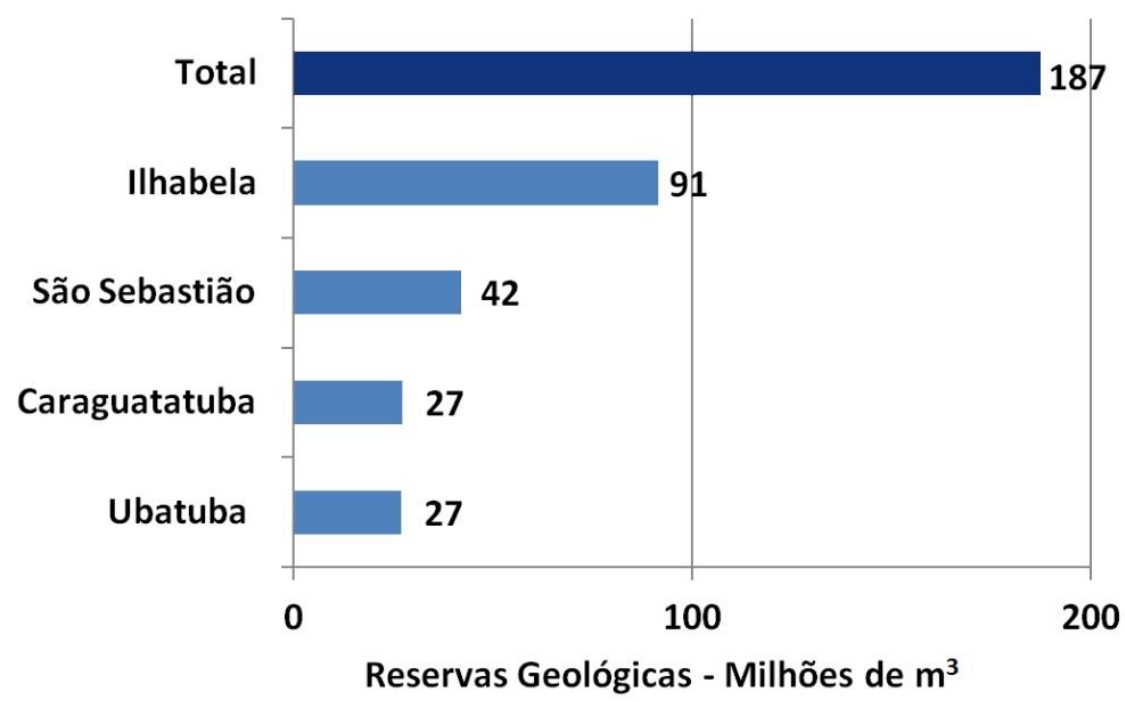

Figura 13. Reservas de materiais de empréstimo em áreas degradadas com alto potencial geológico.

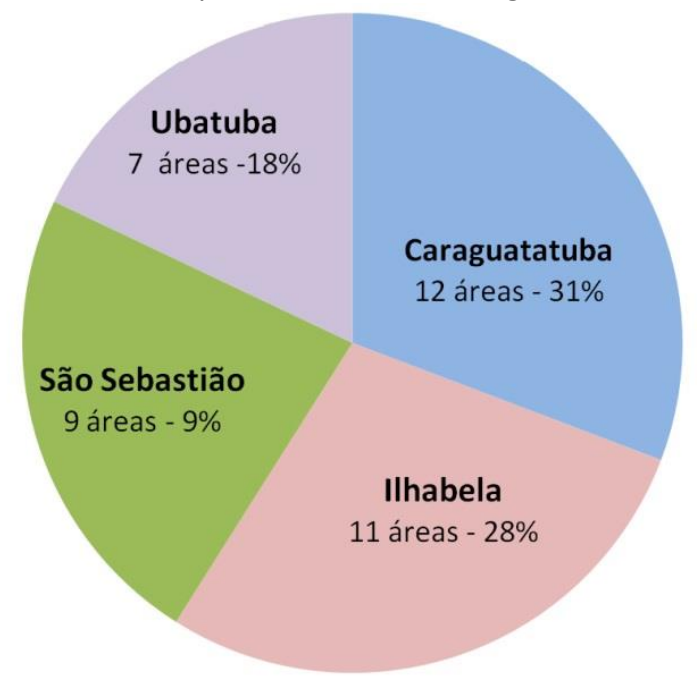

Figura 14. Áreas degradadas com reservas estimadas de materiais de empréstimo superior a 1 milhão de $\mathrm{m}^{3}$ (1,4 milhão de toneladas).

Ao se efetuar uma análise comparativa entre o potencial de reservas estimadas nas áreas degradadas e o consumo de materiais de empréstimo no Litoral Norte, constata-se que a dotação mineral estimada nesses polígonos é plenamente capaz de suportar o consumo atual, situado na faixa de 400.000 a $600.000 \mathrm{~m}^{3} /$ ano (600.000 a 850.000 t/ano), ou mesmo até uma forte expansão da demanda por esse tipo de insumo mineral na região.

As lavras de materiais de empréstimo sobre os mantos de alteração que capeiam os maciços cristalinos conduzem constantemente à exumação de núcleos rochosos menos alterados e, dependendo do nível de aprofundamento das escavações, da própria rocha sã. A adoção de tecnologias apropriadas e amplamente disponível no mercado podem também permitir o aproveitamento de rochas do embasamento cristalino, viabilizando em uma mesma área a produção de várias substâncias de uso intensivo na construção civil, tais como: saibro (materiais de empréstimo comercializados in natura) e areia graduada (produzida por beneficiamento à úmido, envolvendo lavagem, peneiramento e hidrociclonagem em diferentes etapas de classificação) a partir dos mantos de alteração intempérica; e rocha britada, materiais para cantaria, rochas para revestimento e areia manufaturada no processamento de maciços rochosos (Figura 15). 


\section{O USO DE SISTEMAS DE INFORMAÇÕES GEOGRÁFICAS NA IDENTIFICAÇÃO DE ÁREAS PRIORITÁRIAS PARA RECUPERAÇÃO E APROVEITAMENTO MINERAL NO LITORAL NORTE DE SÃO PAULO}

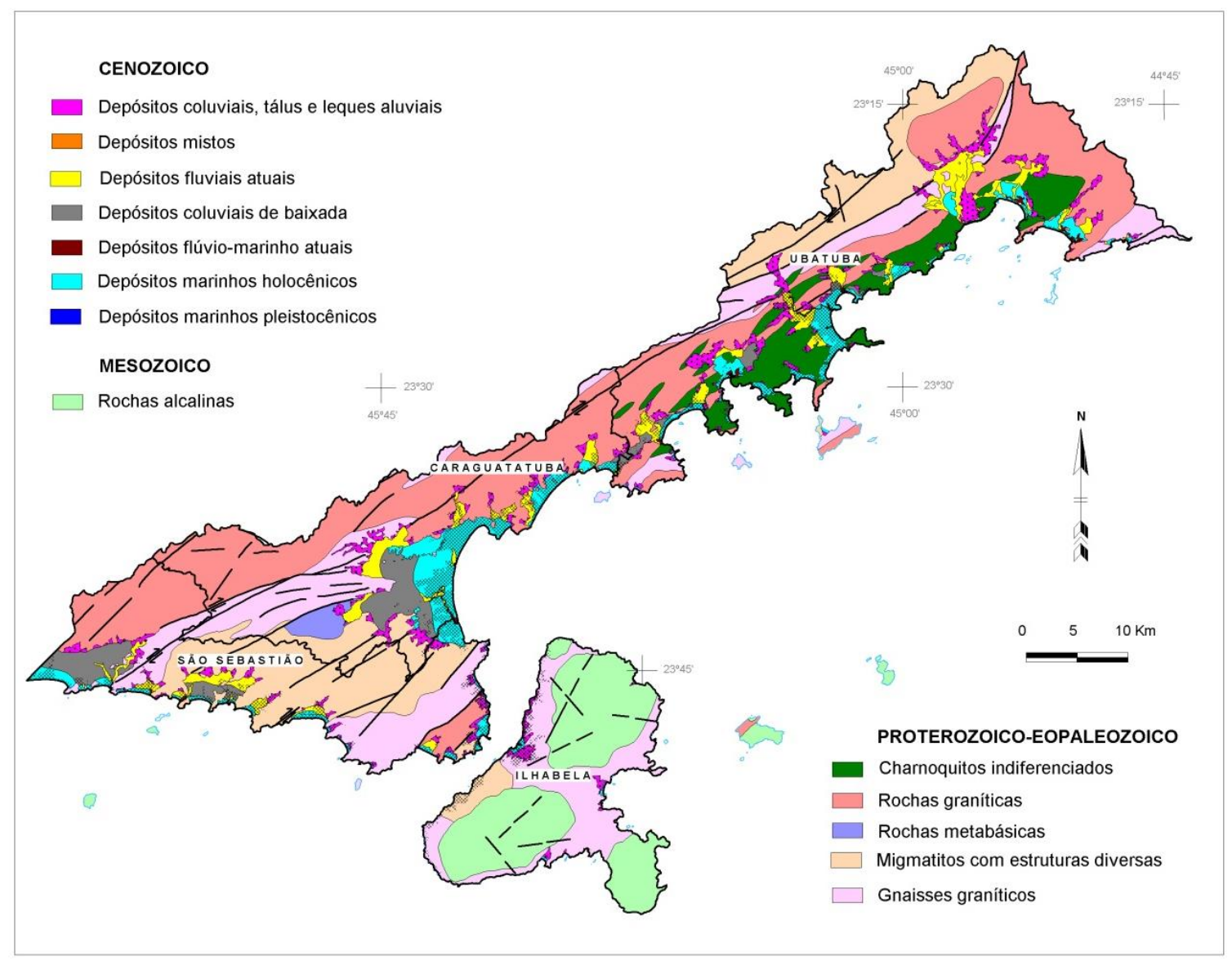

Figura 15. Mapa geológico da área de estudo.

\section{CONCLUSÕES}

O uso das redes triangulares irregulares no cálculo do volume e na identificação do potencial mineral de áreas degradadas no Litoral Norte do estado de São Paulo, mostrou-se eficaz. Comparando-se os resultados obtidos com os alcançados por Ferreira \& Fernandes da Silva (2008), que utilizou grades regulares, observa-se que as respostas são compatíveis. Em ambos os trabalhos, as áreas localizadas no município de Ubatuba, cadastradas como RM-296, RM-336 e RM-368, cujo perímetro não apresentou alteração nos últimos anos, apresentaram alto potencial para o aproveitamento de saibro. Além de fácil implementação, a TIN confeccionada no âmbito deste trabalho apresentou um modelo fiel às condições encontradas em campo.

Com relação à possibilidade de aproveitamento destas áreas, entende-se que o direcionamento da mineração no Litoral Norte, preferencialmente para as áreas degradadas pode trazer múltiplos benefícios: econômicos garantindo a continuidade da atividade e o suprimento de bens minerais de baixo valor unitário de uso intensivo na construção civil; e ambientais - restringindo os empreendimentos de mineração e atividades diretamente agregadas aos sítios já antropizados e suscetíveis ambientalmente, bem como possibilitando a sua reabilitação.

\section{REFERÊNCIAS}

BARBOSA, I.; MELLO, F. L. SILVA, L. F. C. F. Registro de feições sobre a superfície de uma Rede Triangular Irregular. Revista Brasileira de Cartografia, Rio de janeiro, n. 61/01, p. 13-17, 2009.

BITAR, O. Y. Mineração e Usos do Solo no Litoral Paulista: estudo sobre conflitos, alterações ambientais e riscos. 1990 (Dissertação de Mestrado). Instituto de Geociências, Unicamp, Campinas, $162 \mathrm{p}$.

BRASIL. Política Nacional do Meio Ambiente. Lei n.o 6.938 de 31 de agosto de 1981. Brasília: DOU 02/09/1981, p. 16509. Disponível em: http://www.mma.gov.br/port/conama/legiabre.c fm?codlegi=313. Acesso em 28/05/215. 


\section{O USO DE SISTEMAS DE INFORMAÇÕES GEOGRÁFICAS NA IDENTIFICAÇÃO DE ÁREAS PRIORITÁRIAS PARA RECUPERAÇÃO E APROVEITAMENTO MINERAL NO LITORAL NORTE DE SÃO PAULO}

BROLLO, M.J.; FERREIRA, C. J.; FERNANDES DA SILVA, P. C.; TOMINAGA, L.K.; VEDOVELLO, R.; GUEDES, A.C.M; LOPES, E.; OLIVEIRA, A.R.; UMMUS, M.E.; CRIPPS, J.C. 2005. Caracterização das áreas degradadas por mineração de saibro em Ubatuba: condicionantes para a recuperação ambiental. In: CONGR. BRAS. GEOLOGIA DE ENGENHARIA E AMBIENTAL, 11, 2005, Florianópolis: ABGE, 13 de novembro de 2005, p. 918-933.

CABRAL JUNIOR, M; GAMBA, C.T.C.; OBATA, O.R. Ordenamento Territorial Geomineiro do Litoral Norte do Estado de São Paulo. Revista Brasil Mineral, São Paulo, n. 341, p. 46-52, 2014.

FELGUEIRAS, C. A. Modelagem Numérica do Terreno. In: CÂMARA, G.; DAVIS, C.; MONTEIRO, A. M. V. (Org.) Introdução á Ciência da Geoinformação. São José dos Campos: INPE, 2001. P. 7.1-7.38

FERREIRA C. J. (coord.) Diretrizes para a regeneração socioambiental de áreas degradadas por mineração de saibro (caixas de empréstimo), Ubatuba, SP. Relatório Técnico 2, FAPESP (processo FAPESP 03/07182-5), p. 11-98, 2005.

FERREIRA C.J.; FERNANDES-DA-SILVA, PC.; FURLAN, S.A.; BROLLO M.J.; TOMINAGA, L.K.; VEDOVELLO, R.; GUEDES, A.C.M.; FERREIRA, D.F.; EDUARDO, A.S.; AZEVEDO SOBRINHO, J.M.; LOPES, E.; CRIPPS, J.C.; PERES, F.; ROCHA, G. Devising strategies for reclamation of derelict sites due to mining of residual soil (Saibro) at Ubatuba, North Coast of Sao Paulo State, Brazil: the views and roles of stakeholders. Sociedade \& Natureza, Uberlândia, Special Issue, p. 643-660, 2005.

FERREIRA, C.J. Hazards related to small mining of minerals for use in construction (sand, stone and residual soil) in the North Coast of State of Sao Paulo, Brazil. In: INTERNATIONAL DISASTER REDUCTION CONFERENCE, 2006, Davos: Swiss Federal Institute WSL, 2006. v. 1. p. 250.

FERREIRA, C.J.; FERNANDES DA SILVA, P.C. O uso de sistema de informações geográficas na priorização de áreas para aproveitamento mineral de saibro em áreas degradadas, Ubatuba, SP. Revista do Instituto Geológico, São Paulo, v. 29, p. 19-31, 2008.
FERREIRA, C. J.; BROLLO, M. J.; UMMUS, M. E.; NERY, T. D.. Indicadores e quantificação da degradação ambiental em áreas mineradas, Ubatuba (SP). Revista Brasileira de Geociências, São Paulo, v.38, n.1, p. 153-166, 2008a.

FERREIRA, C. J. ; VEDOVELLO, R. ; SCIOTTA, L. C. ; FERNANDES-DA-SILVA, P. C. . Definição e análise dos indicadores de degradação ambiental associada às áreas mineradas no município de Caraguatatuba, SP. In: CONGRESSO BRASILEIRO DE GEOLOGIA DE ENGENHARIA E AMBIENTAL, 12, 2008, Porto de Galinhas: Associação Brasileira de Geologia de Engenharia e Ambiental, 18 de novembro de 2008b, p.1-12 (CD-ROM).

FERREIRA, C. J.; FERNANDES-DA-SILVA, P. C. ; BROLLO, M. J. ; CRIPPS, J. C. . Dereliction problems from exploitation of residual soil and ornamental stone at Ubatuba. In: Culshaw, M.G.; Reeves, H.J.; Jefferson, I.; Spink, T.W.. (Org.). Engineering Geology for Tomorrow's Cities, Bath: The Geological Society Publishing House, 2009, v. 22, 10 p. (CD-ROM).

FERREIRA, C. J. Análise de risco a escorregamento e quantificação da degradação em apoio ao licenciamento ambiental da mineração, Litoral Norte, SP. In: CONGRESSO BRASILEIRO SOBRE DESASTRES NATURAIS, 2012, Rio Claro: UNESP/IG, 14 de maio de 2012, p. 1-9. GAMBA, C.T.C. (coord.) Bases técnicas para o ordenamento territorial da mineração nos municípios do Litoral Norte paulista. São Paulo: IPT (Rel. IPT no 133.407-205), 2013.

LEE, J. Comparsion of existing methods for building triangular irregular network models of terrain from grid digital elevation models. International Journal of Geography Information Systems, Abingdon, v. 5, n. 3, p. 267-285, 1991.

NAMIKAWA, L. M. A method for triangular grid surface fitting using breaklines. International Archives of Photogrammetry and Remote Sensing, v.30, n. 4, p. 362-368, 1994.

NOGUEIRA, F. R.; MORETTI, R. S.; PAIVA, C. F.E. Estudos sobre riscos geológicos e sua incorporação no planejamento territorial relato da experiência de formação de quadros técnicos no $A B C$ paulista. Revista Brasileira de Geologia de Engenharia e Ambiental, v. 3, n.1, p. 45-56, 2013. 
PITERI, M. A.; MENEGUETTE JUNIOR, M.; SANTOS, A. G.; OLIVEIRA, F. F. Triangulação de Delaunay e o Princípio de Inserção Randomizado. In: Simpósio Brasileiro de Geomática, 2, 2007, Presidente Prudente: UNESP/UFPR, 24-27 de julho de 2002, p. 655-663.

SAATY, T. L. Decision making with analytic hierarchy process. International Journal of Services Science, V. 1, n.1, p. 83-98, 2008. 